\title{
Prevention of diabetic foot complications
}

\author{
Aziz Nather ${ }^{1}$, FRCSE, Shuo $\underline{\text { Cao }}^{1}$, Jamie Li Wen $\underline{C h e n}^{1}$, An Yee $\underline{L o w}^{1}$
}

\begin{abstract}
This paper discussed the importance of prevention of diabetic foot ulcers and our institution's protocol for prevention, reviewing the existing evidence in the literature regarding the effectiveness of the preventive approach. Diabetes mellitus is the second most significant cause of disease in Singapore after ischaemic heart disease. National University Hospital, Singapore, adopts a two-pronged strategy for the management of diabetic foot ulcers. The most important strategy is prevention, and education is key. Education should mainly be directed at patients and caregivers, but also professionals (general practitioners, allied health professionals and nurses) so that they can effectively educate patients and caregivers. Patient education includes care of diabetes mellitus, care of the foot and use of appropriate footwear. Patients also tend to have poor foot hygiene. Annual foot screening for diagnosed diabetics plays an important role. However, prolonged and sustained government intervention is necessary to provide education and screening on a national scale.
\end{abstract}

Keywords: annual foot screening, care of diabetes, care of foot and choice of footwear, education, prevention of diabetic foot wounds

\section{INTRODUCTION}

Diabetes mellitus is on the rise in Singapore. It is now the second most significant cause of ill-health and disease in Singapore after ischaemic heart disease, affecting one in nine Singaporeans. One in three diabetics do not know that they have the condition, and among known diabetics, one in three have poor control of their condition. ${ }^{(1)}$ Currently, Singapore has the second-highest proportion of diabetics among developed countries after the United States. ${ }^{(2)}$ Indeed, Asians are becoming more at risk for diabetes mellitus due to rising incomes and the prevalence of unhealthy lifestyles. ${ }^{(3)}$ Asians have a higher percentage of body fat than their Western counterparts. ${ }^{(4)}$ Diabetes mellitus cost Singapore SGD 1 billion in 2010, and this figure is projected to rise to SGD 2.5 billion by 2050. The cost per working-age person is also projected to increase from SGD 7,678 in 2010 to SGD 10,596 in $2050 .^{(3)}$

The key to management of diabetic foot wounds is prevention. The lifetime risk of developing a foot ulcer is $15 \%$, ${ }^{(5)}$ while in diabetics, the incidence of developing an ulcer may be as high as $25 \% .{ }^{(6)}$ Once an ulcer has developed, there is a high risk of it leading to below-knee amputation. Limb amputations are the most costly and feared consequence of foot ulcers. In diabetics, $84 \%$ of non-traumatic limb amputations are preceded by foot ulcers. ${ }^{(7)}$ This group is 25 times more at risk of a limb amputation as compared to people without diabetes mellitus. ${ }^{(8)}$

This paper aimed to discuss the importance of prevention and our protocol for prevention - in the form of education and foot screening - and to review the existing evidence in the literature regarding the effectiveness of the preventive approach.

\section{STRATEGY FOR DIABETIC FOOT MANAGEMENT}

Fig. 1 summarises our algorithm for the prevention of diabetic foot wounds. Both professional and patient education, and foot screening are required to prevent diabetic foot problems, with the help of government intervention to run education and screening programmes on a national scale. Our institution, the National University Hospital, Singapore, adopts a two-pronged strategy in treating diabetic foot wounds. The first strategy is to prevent foot wounds. However, if a wound develops, it should be treated by an interdisciplinary diabetic foot team in a hospital.

\section{Education as the most important strategy}

The key to prevention of diabetic foot problems is education. While this should be mainly directed at patients and caregivers, professionals must first be educated so that they understand the nature of patient education. Once trained and educated, they can then provide effective education for patients and caregivers.

There is controversy in the literature about the effectiveness of patient education in preventing diabetic foot ulcer (Table I). With regard to preventing ulceration and below-knee amputation, Malone et $\mathrm{al}^{(9)}$ found, in a randomised controlled study, that the amputation rate in the control group was three times higher than that in the intervention group $(p<0.05)$. In addition, McMurray et al, ${ }^{(10)}$ in a randomised controlled study involving end-stage renal failure patients, found significant improvement in self-knowledge in the intervention group $(p<0.001)$. They also found five amputations in the control group, versus no amputations in the intervention group $(p<0.05)$. In a blinded randomised controlled trial, Litzelman et $\mathrm{al}^{(11)}$ also found the intervention group to be less likely to develop foot lesions $(p=0.05)$. The intervention group also demonstrated self-foot care behaviour $(p<0.001)$. However, Lincoln et al, ${ }^{(12)}$ in an observer-blinded randomised controlled study, reported no significant difference in the two groups in terms of ulcer incidence at six months and amputation rate. The effectiveness of patient education may depend on the type of teaching pedagogy employed. ${ }^{(13)}$ While Kruger et al $^{(14)}$ reported 
Table I. Studies of patient education programmes.

\begin{tabular}{|c|c|c|c|c|c|}
\hline Author, yr & $\begin{array}{l}\text { Intervention/control } \\
\text { groups (No.) }\end{array}$ & Intervention & $\begin{array}{l}\text { Duration of } \\
\text { intervention }\end{array}$ & $\begin{array}{l}\text { Duration of } \\
\text { follow-up }\end{array}$ & Outcome \\
\hline $\begin{array}{l}\text { Malone et al, } \\
1989^{(9)}\end{array}$ & $\begin{array}{l}103 \text { (203 limbs)/ } \\
100 \text { (193 limbs) }\end{array}$ & $\begin{array}{l}\text { 1-hr foot care lesson vs. } \\
\text { general education }\end{array}$ & $1 \mathrm{hr}$ & $2 \mathrm{yr}$ & $\begin{array}{l}\text { Significantly lower amputation } \\
\text { rate }(4.0 \% \text { vs. } 11.9 \%, p<0.025) \text {, } \\
\text { lower ulceration rate } \\
(4.5 \% \text { vs. } 14.7 \%, p=0.002)\end{array}$ \\
\hline $\begin{array}{l}\text { McMurray et al, } \\
2002^{(10)}\end{array}$ & $45 / 38$ & $\begin{array}{l}\text { Individualised diabetic } \\
\text { education vs. standard } \\
\text { care without education }\end{array}$ & $1 \mathrm{yr}$ & $1 \mathrm{yr}$ & $\begin{array}{l}\text { Improvement in } \\
\text { self-management behaviour } \\
(p<0.001) \text {, lower amputation } \\
\text { rate in intervention group } \\
(13.2 \% \text { vs. } 0 \%, p<0.05)\end{array}$ \\
\hline $\begin{array}{l}\text { Lincoln et al, } \\
2008^{(12)}\end{array}$ & $87 / 85$ & $\begin{array}{l}\text { Education session vs. } \\
\text { usual care }\end{array}$ & $4 w k$ & $1 \mathrm{yr}$ & $\begin{array}{l}\text { No significant difference in ulcer } \\
\text { incidence and amputation rate }\end{array}$ \\
\hline $\begin{array}{l}\text { Litzelman et al, } \\
1993^{(11)}\end{array}$ & $191 / 205$ & $\begin{array}{l}\text { Foot care sessions vs. } \\
\text { usual care }\end{array}$ & $1 \mathrm{yr}$ & $1 \mathrm{yr}$ & $\begin{array}{l}\text { Intervention group less likely to } \\
\text { develop foot ulcer }(p=0.05) \\
\text { had better foot care behaviour }\end{array}$ \\
\hline $\begin{array}{l}\text { Kruger et al, } \\
1992^{(14)}\end{array}$ & $23 / 27$ & $\begin{array}{l}\text { Hands-on session with } \\
\text { lecture vs. lecture alone }\end{array}$ & $1 \mathrm{wk}$ & $6 \mathrm{mth}$ & Hands-on session ineffective \\
\hline $\begin{array}{l}\text { Gershater et al, } \\
2011^{(13)}\end{array}$ & $40 / 58$ & $\begin{array}{l}\text { Group discussion vs. } \\
\text { didactic teaching }\end{array}$ & $1 \mathrm{hr}$ & $6 \mathrm{mth}$ & $\begin{array}{l}\text { Higher ulceration rate } \\
(48 \% \text { vs. } 38 \%) \text { in intervention } \\
\text { group }\end{array}$ \\
\hline
\end{tabular}

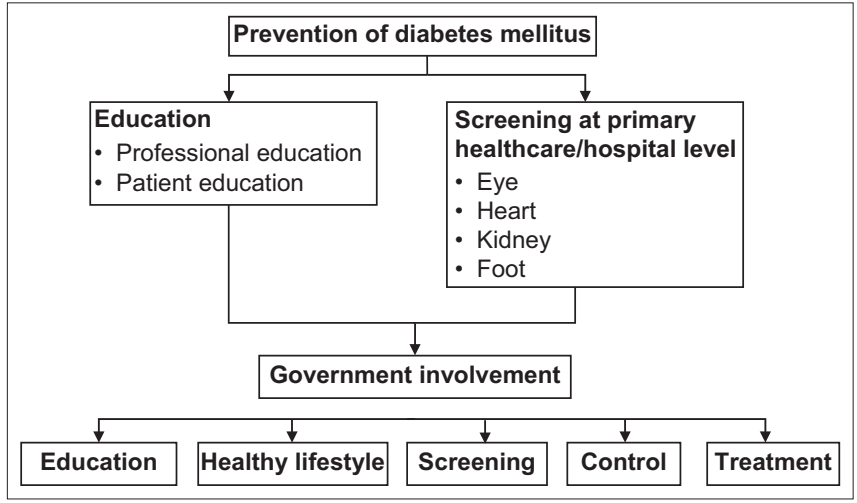

Fig. 1 Algorithm for prevention of diabetes mellitus and diabetic foot.

that hands-on teaching was ineffective compared to didactic teaching, Gershater et $\mathrm{al}^{(13)}$ showed that group discussion is not an ideal method (Table I). More research is needed on the effectiveness of different teaching methodologies utilised.

Despite the controversy regarding the usefulness of patient education, several guidelines have recommended that care of the foot be taught to patients and caregivers ${ }^{(15-18)}$ along with the use of appropriate footwear. ${ }^{(15,16)}$ The International Working Group on the Diabetic Foot strongly recommended education on footwear and encouraged education for foot care. ${ }^{(16)}$

Professionals who require education include general practitioners, doctors, nurses and allied health professionals in hospitals and primary healthcare centres. Box 1 shows educational materials such as books, websites and guidelines that are available for training professionals.

Nevertheless, the main thrust of our education efforts should be directed at patients and caregivers. Education must be provided in three different areas: care of diabetes mellitus, care of the foot and choice of footwear. We found that patients usually do not understand diabetes mellitus and do not manage it well. They often present with a glycated haemoglobin ( $\mathrm{HbA} 1 \mathrm{c})$ level of $10.0 \%$ or more. In our 2014 study on the effectiveness of the multidisciplinary team approach to treat diabetic foot, $45 \%$ in a cohort of 206 patients had a HbA1c level of more than $10 \%$. $^{(25)}$ Hence, our education efforts should focus on first teaching patients about diabetes mellitus and its care, including diet, exercise and medication. Next, we must educate them on foot hygiene and care of the foot. Finally, attention must be given to the use of appropriate footwear.

Patient education materials that are available include books ${ }^{(26)}$ and online materials (Box 2). Other materials include patient education pamphlets given by institutions. The pamphlets given to patients in our hospital included 'Knowing Diabetes', 'Happy Feet' and 'Patients' Guide for Footwear'. ${ }^{(17)}$

\section{Foot screening}

The effect of foot screening in reducing diabetic foot wounds is controversial. Lavery et $\mathrm{al}^{(27)}$ showed that a combination of foot screening and education was able to decrease the incidence of amputation by $47.4 \%(p<0.05)$, as well as reduce average inpatient length of stay by $21.7 \%(p<0.05)$. However, in a retrospective case-control study involving 61 Pima Indian patients with prior amputation and 183 controls without prior amputation, Mayfield et $\mathrm{al}^{(28)}$ found that receiving one or more foot care examinations does not significantly reduce the risk of amputation $(p=0.31)$. More prospective research is needed.

In addition, the frequency of foot screening may affect its outcome. More research is needed to evaluate the effect of different frequencies employed. In our hospital, all diabetic patients are subjected to annual foot screening in addition to yearly eye screening, heart screening and kidney screening. ${ }^{(29)}$ The strategy of the Ministry of Health, Singapore, is to screen diagnosed diabetics as early as possible at the primary healthcare level. 


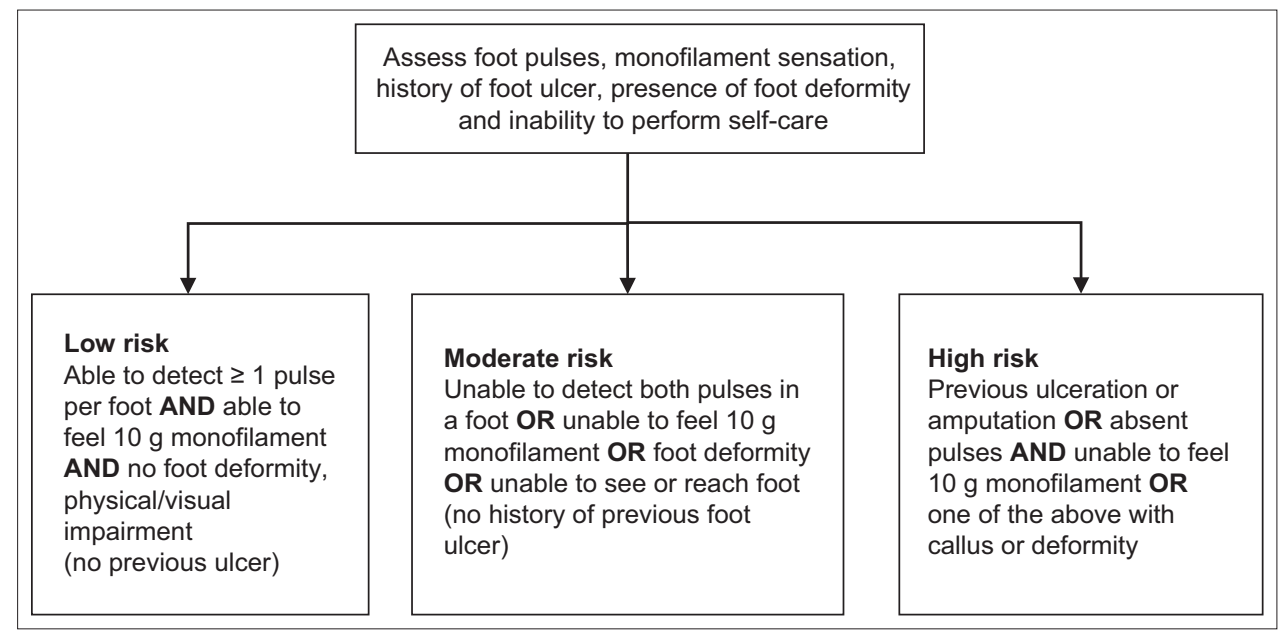

Fig. 2 Foot risk stratification scheme. ${ }^{(30)}$

\begin{tabular}{|c|c|}
\hline \multicolumn{2}{|c|}{ Box 1. Materials for professional education. } \\
\hline Books & $\begin{array}{l}\text { Clinical Care of the Diabetic Foot, Armstrong } \\
\text { DG (2005)(19) } \\
\text { Diabetic Foot Problems, Nather A (2008) }{ }^{(20)} \\
\text { Levin and O'Neal's The Diabetic Foot, Bowker JH \& } \\
\text { Pfeifer MA (2008) } \\
\text { The Diabetic Foot, Nather A }(2012)^{(22)} \\
\text { Surgery for Diabetic Foot: a Practical Operative } \\
\text { Manual, Nather A }(2016)^{(23)}\end{array}$ \\
\hline Websites & $\begin{array}{l}\text { International Diabetes Federation (https://www. } \\
\text { idf.org) } \\
\text { American Diabetes Association (http://www. } \\
\text { diabetes.org) } \\
\text { Centers for Disease Control and } \\
\text { Prevention (https://www.cdc.gov/diabetes) }\end{array}$ \\
\hline Guidelines & $\begin{array}{l}\text { IWGDF Guidance on the management and } \\
\text { prevention of foot problems in diabetes } 2015^{(16)} \\
\text { Diabetic foot problems: prevention and } \\
\text { management, NICE guideline } 2015^{(15)} \\
\text { Best practice guideline for ASEANPIus: } \\
\text { management of diabetic foot wounds }{ }^{(17)} \\
2012 \text { Infectious Diseases Society of America } \\
\text { clinical practice guideline for the diagnosis and } \\
\text { treatment of diabetic foot infections } \\
\text { (24) }\end{array}$ \\
\hline
\end{tabular}

Box 2. Materials for patient education.

Books Type 2 Diabetes Basics, International Diabetes Center (2014) (26)

Websites American Diabetes Association DiabetesPro Patient Education Library (https://professional.diabetes. org/content/patient-education-library) Diabetic Living (http://www.diabeticlivingonline. com)

\section{The 'foot at risk'}

The purpose of foot screening is to detect signs of the 'foot at risk'. This refers to a foot with the potential to ulcerate. The four key signs of the foot at risk are loss of protective sensation (peripheral neuropathy), one or both distal pulses not being palpable (peripheral arterial disease), presence of foot deformity or callosity, and inability to reach the foot or visual impairment. ${ }^{(16)}$ The risk stratification tool by Leese et al can be used to predict the risk of foot ulceration. ${ }^{(30)}$ The tool classifies the foot into one of three categories: low, moderate or high risk (Fig. 2). This stratification is based on four clinical criteria: patient history, foot pulses, monofilament testing and foot deformity.

\section{Methods of foot screening}

There is no standardised protocol for foot screening. The different screening methodologies used by the various institutions are shown in Table II.

Our institution's protocol consists of clinical history and examination (including neurological and vascular assessment), measurement of the ankle-brachial index (ABI) and toe-brachial index (TBI), the monofilament test and neurothesiometer test, foot risk stratification, foot care education and a management plan. ${ }^{(29)} \mathrm{ABI} / \mathrm{TBI}$ measurement is not done in the American Diabetes Association's protocol and the NHS (National Health Services) Scotland's protocol. Singapore's Ministry of Health intends to conduct foot screening on a national level, and future screenings will not include $\mathrm{ABI} / \mathrm{TBI}$ and neurothesiometer measurement. Foot screening aims to detect the foot at risk, including the absence of a palpable pulse (can be detected clinically). Hence, there is no need for the ABI/TBI, which requires additional equipment and taking up more steps for screening. Furthermore, the monofilament test is able to reveal the clinical presence or absence of neuropathy, and therefore, the neurothesiometer is also not necessary.

\section{Government intervention}

In the United States, the country with the highest proportion of diabetic patients among developed countries, ${ }^{(2)}$ the government of each state funds national campaigns and programmes to lower the prevalence of diabetes mellitus. The United Kingdom has implemented the DESMOND (Diabetes Education and Selfmanagement for Ongoing and Newly Diagnosed) programme since 2003. This programme has not made a significant impact on glycaemic control, but has shown a better understanding of diabetes mellitus among patients. ${ }^{(34)}$

Government involvement is crucial for successful prevention on a national scale. It is noteworthy that the Minister for Health, Singapore, 'declared a war on diabetes'(1) in April 2016. It 
Table II. Different foot screening methods.

\begin{tabular}{|ll|}
\hline Protocol & Foot screening method \\
\hline NUH protocol $^{(29)}$ & Patient history \\
& Clinical exam \\
& Monofilament test/ \\
& neurothesiometer \\
& Ankle-brachial/toe-brachial index \\
& Patient education \\
\hline Ipswich protocol (31) & Patient history \\
& Clinical exam \\
& Ipswich Touch Test \\
& Patient education \\
\hline ADA protocol & Patient history \\
& Clinical exam \\
& Monofilament test/tuning fork/ \\
& neurothesiometer \\
& Patient education \\
& Patient history \\
& Clinical exam \\
NHS Scotland protocol ${ }^{(33)}$ & Monofilament \\
& Patient education \\
\hline
\end{tabular}

ADA: American Diabetes Association; NHS: National Health Services NUH: National University Hospital

initiated two ministerial task forces, one on Diabetes Prevention and Care and a second task force to promote a healthy lifestyle. Such government intervention needs to be long and sustained. Intervention is important not only to address diabetes but also other chronic related diseases, such as hypertension, ischaemic heart disease, stroke and renal impairment.

\section{CONCLUSION}

In conclusion, the key to management of diabetic foot wounds is prevention, and our main efforts should be put into education. Foot screening also plays an important role. However, for prevention efforts to be effective, prolonged and sustained government involvement is needed.

\section{REFERENCES}

1. Khalik S. Parliament: Health Minister Gan Kim Yong declares 'war on diabetes', new task force set up. In: The Straits Times [online]. Available at: http://www. straitstimes.com/singapore/health/moh-declares-war-against-diabetes. Accessed July 21, 2016

2. International Diabetes Federation. IDF Diabetes Atlas Seventh Edition 2015. Available at: http://www.diabetesatlas.org/component attachments/?task=download\&id=116. Accessed May 9, 2016

3. Png ME, Yoong J, Pham TP, Wee HL. Current and future economic burden of diabetes among working-age adults in Asia: conservative estimates for Singapore from 2010-2050. BMC Public Health 2016; 16:153.

4. Wang J, Thornton JC, Russell M, et al. Asians have lower body mass index (BMI) but higher percent body fat than do whites: comparisons of anthropometric measurements. Am J Clin Nutr 1994; 60:23-8.

5. Reiber GE. The epidemiology of diabetic foot problems. Diabet Med 1996; 13 suppl 1:S6-11.

6. Singh N, Armstrong DG, Lipsky BA. Preventing foot ulcers in patients with diabetes. JAMA 2005; 293:217-28.

7. Brem H, Sheehan P, Rosenberg HJ, Schneider JS, Boulton AJ. Evidence-based protocol for diabetic foot ulcers. Plat Reconstr Surg 2006; 117 (7 Suppl):193S-209S.
8. International Diabetes Federation. International Working Group on the Diabetic Foot. Available at: http://www.idf.org/webdata/docs/background_info_AFR.pdf. Accessed May 9, 2016.

9. Malone JM, Snyder M, Anderson G, et al. Prevention of amputation by diabetic education. Am J Surg 1989; 158:520-3; discussion 523-4.

10. McMurray SD, Johnson G, Davis S, McDougall K. Diabetes education and care management significantly improve patient outcomes in the dialysis unit. Am J Kidney Dis 2002; 40:566-75.

11. Litzelman DK, Slemenda CW, Langefeld CD, et al. Reduction of lower extremity clinical abnormalities in patients with non-insulin-dependent diabetes mellitus. A randomized, controlled trial. Ann Intern Med 1993; 119:36-41.

12. Lincoln NB, Radford KA, Game KL, Jeffcoate WJ. Education for secondary prevention of foot ulcers in people with diabetes: a randomised controlled trial. Diabetologia 2008; 51:1954-61.

13. Gershater MA, Pilhammar E, Apelqvist J, Alm-Roijer C. Patient education for the prevention of diabetic foot ulcers. Eur Diabetes Nurs 2011; 8:102-107b.

14. Kruger S, Guthrie D. Foot care: knowledge retention and self-care practices. Diabetes Educ 1992; 18:487-90.

15. National Institute for Health and Care Excellence. Diabetic foot problems: prevention and management. Available at: https://www.nice.org.uk/ guidance/ng 19/resources/diabetic-foot-problems-prevention-andmanagement-1837279828933. Accessed March 2, 2018.

16. International Diabetes Federation. International Working Group on the Diabetic Foot. Prevention and Management of Foot Problems in Diabetes Guidance Documents and Recommendations. Available at: http://iwgdf.org/guidelines/. Accessed March 2, 2018.

17. Nather A, Soegondo S, Adam JMF, et al. Best practice guidelines for ASEANPlus: management of diabetic foot wounds. Sri Lanka Journal of Diabetes Endocrinology and Metabolism 2015;1-37.

18. American Diabetes Association. Standards of Medical Care in Diabetes-2016. Diabetes Care 2016; 39 Suppl 1.

19. Armstrong DG. Clinical Care of the Diabetic Foot. $3^{\text {rd }}$ ed. Alexandria, VA: American Diabetes Association, 2015.

20. Nather A. Diabetic Foot Problems. Singapore: World Scientific, 2008.

21. Bowker JH, Pfeifer MA. Levin and O'Neal's The Diabetic Foot. Missouri: Mosby, 2008.

22. Nather A. The Diabetic Foot. Singapore: World Scientific, 2012.

23. Nather A. Surgery for Diabetic Foot: a Practical Operative Manual. Singapore: World Scientific, 2016.

24. Lipsky BA, Berendt AR, Cornia PB, et al; Infectious Diseases Society of America. 2012 Infectious Diseases Society of America clinical practice guideline for the diagnosis and treatment of diabetic foot infections. Clin Infect Dis 2012; 54:e132-73.

25. Nather A, Shuo C, Liang S, et al. Team approach in the management of diabetic foot wounds - the National University Hospital Experience. Orthopaedic Surgery and Traumatology 2016; 1:29-34.

26. International Diabetes Center. Type 2 Diabetes Basics. Minneapolis: IDC Publishing, 2014

27. Lavery LA, Wunderlich RP, Tredwell JL. Disease management for the diabetic foot: effectiveness of a diabetic foot prevention program to reduce amputations and hospitalizations. Diabetes Res Clin Pract 2005 Oct; 70:31-7.

28. Mayfield JA, Reiber GE, Nelson RG, Greene T. Do foot examinations reduce the risk of diabetic amputation? J Fam Pract 2000; 49:499-504.

29. Nather A, Voon ASL. Foot screening. In: Nather A, eds. The Diabetic Foot. Singapore: World Scientific, 2012: 157-66.

30. Leese G, Schofield C, McMurray B, et al. Scottish foot ulcer risk score predicts foot ulcer healing in a regional specialist foot clinic. Diabetes Care 2007; 30:2064-9.

31. Rayman G, Vas PR, Baker N, Taylor CG, Gooday C, Alder AI, Donohoe M. The Ipswich Touch Test: a simple and novel method to identify inpatients with diabetes at risk of foot ulceration. Diabetes Care 2011; 34:1517-18.

32. Boulton AJ, Armstrong DG, Albert SF, et al. Comprehensive foot examination and risk assessment: a report of the task force of the foot care interest group of the American Diabetes Association, with endorsement by the American Association of Clinical Endocrinologists. Diabetes Care 2008; 31:1679-85.

33. NHS Highland. Foot Screening. Available at: http://www.nhshighland.scot.nhs. uk/YourHealth/Diabetes/Pages/FootScreening.aspx. Accessed April 3, 2016.

34. Davies MJ, Heller S, Skinner TC, et al. Effectiveness of the diabetes education for ongoing and newly diagnosed (DESMOND) programme for people with newly diagnosed type 2 diabetes: cluster randomised controlled trial. BMJ 2008; 336:491-95. 